\title{
境界要秦法と有限要素法の結合解法による応力拡大係数解析* （軸対称问題に対する適用）
}

\author{
宮 崎 則 幸*1, 池 田徹*2 \\ 伊東謙 一*3, 宗像 健 ${ }^{* 1}$

\section{Stress Intensity Factor Analysis by Combination of Boundary Element and FiniteElement Methods \\ (Application to Axisymmetric Crack Problems)} \\ Noriyuki MIYAZAKI, Toru IKEDA, \\ Kenichi ITO and Tsuyoshi MUNAKATA
}

\begin{abstract}
This paper presents the stress intensity factor analysis of axisymmetric crack problems. A stress analysis is performed with the combination of the boundary element method and the finite element method, and then the stress intensity factor is calculated by the virtual crack extension method. First, the stress intensity factor analysis of a circumferential crack in a cylindrical bar under tension is performed and the results are compared with reference solutions to check the applicability of the present method. Then the problems of a crack in an outer or inner wall of a pipe under tension are analyzed. Approximate equations of the stress intensity factor for both problems are proposed.
\end{abstract}

Key Words: Fracture Mechanics, Stress Intensity Factor, Boundary Element Method, Finite Element Method. Virtual Crack Extension Method

\section{1. 緒}

応力拡大係数 (以降, $K$ 值と呼ぶ) は，構造物の破壊 現象に関するパラメータとして重要であるが,これを 解析的に求めることは通常困難であり, 数值解析手法 を用いることが一般に行われている。

特に, 有限要素法 (FEM) は, 最も広く用いられてい る手法でありここにより $K$ 值を求める方法も種々 考案されている。

この中で, よく用いられている方法の一つに, エネ ルギー法の一種である仮想き裂進展法 ${ }^{(1)(2)}$ がある。こ の方法は，1回の解析でき裂のエネルギー解放率を算 出でき，また，比較的粗い要素分割でも高精度な解析 が行えるといった特色を持っている。

一方, 近年, 境界要素法 (BEM) が，有限要素法と並 んで構造物の応力解析に利用されることが多くなって きた，BEMは，境界のみを離散化すればよいことか ら，FEMに比較して，著しくデータ入力の労力を軽 隇することができる特質を持っている。

* 源稿受付 神成 2 年 2 月 21 E。

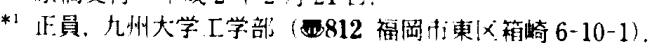

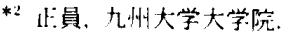

*3 九州大学 T:学部.

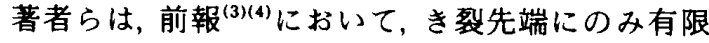
要素を配し，その他の領域を境界要素法によって敖散 化する結合解法に仮想き裂進展法を組込む方法を提案 し、これによって, BEMの入力の労力を軽減できる という特質と仮想き裂進展法の特質の両方を生かすこ とが可能であることを示した。

前報においては，二次元問題に対する適用例のみを 示したが，本報では，これを軸対称問題に適用した結 果を示す。

\section{2. 解 析 方 法}

図 1 に境界要素法と有限要素法の結合解析の概念図 を示す。すなわち，き裂周辺の領域 $\Omega^{F}$ を有限要素法 で，その他の領域 $\Omega^{B}$ を境界要素法で離散化し，これ

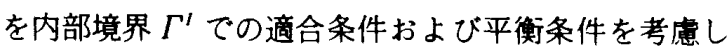
て結合する。

まず， $\Omega^{B}$ について，軸対称問題に対する境界要素 法の基礎式は次式のように与えられる。

$$
\begin{gathered}
C_{i j}(P) u_{j}(P)+2 \pi \int_{\Gamma} p_{i j}^{*}(P, Q) u_{j}(Q) r(Q) d \Gamma \\
\quad=2 \pi \int_{\Gamma} u_{i j}^{*}(P, Q) p_{j}(Q) r(Q) d \Gamma \quad \cdots \cdots \cdots(1)
\end{gathered}
$$

ここで $u_{j}, p_{j}$ は境界上の点での変位および表面力を， 
$r$ は対称軸から $\mathrm{Q}$ 点までの距離を示す。また, $u_{i j}^{*}(P$,

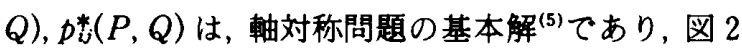
に示すような座標系において, $\mathrm{P}$ 点に $i$ 方向単位軸対 称荷重が作用するときの $\mathrm{Q}$ 点において生じるj方向 の変位および表面力を示す． $C_{i j}$ は $\mathrm{P}$ 点が領域内部に あるとき，次式のようになる。

$$
C_{i j}= \begin{cases}1 & (i=j) \\ 0 & (i \neq j)\end{cases}
$$

また，P点が境界上にあるとき， $C_{i j}$ は境界形状に よって決まる係数である. 通常の二次元問題や三次元 問題においては，㓮体変位条件を用いてこれを求める ことができるが，軸対称問題においては $r$ 方向に㣚体 移動することができない，そこで， $z$ 軸方向には剛体 変位条件を適用し， $r$ 方向については，等温膨張の熱 伸びを拘束することにより生じる応力が一様である条 件を利用することにより， $C_{i j}$ を決定した ${ }^{(6)}$.

さらに, 領域 $\Omega^{B}$ の境界を雄散化して点 $\mathrm{P}$ と点 $\mathrm{Q}$ を関係づけることにより, 次式のような系全体のマト リックス方程式を得る。

$$
\boldsymbol{H U}_{B}=\boldsymbol{G P} \boldsymbol{P}_{B}
$$

ここで, $\boldsymbol{H}, \boldsymbol{G}$ は俰数マトリックス, $\boldsymbol{U}_{B}, \boldsymbol{P}_{B}$ はそれぞ $れ \Omega^{B}$ の境界上での節点変位べクトル, 節点表面力べ クトルを表す.式 (3)に左から $\boldsymbol{G}^{-1}$ と節点表面力べク トルを節点力ベクトルに変換するマトリックス $\boldsymbol{M}$ を 作用させることにより，次式のような有限要素形の方 程式が得られる。

$$
K_{B} U_{B}=M P_{B}=F_{B}
$$

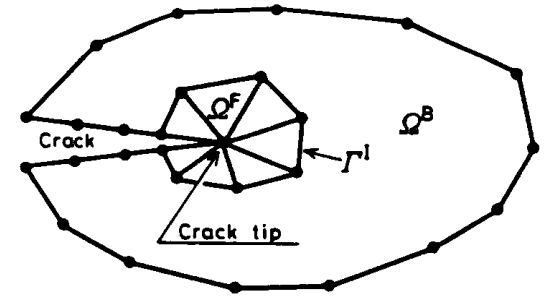

図 1 BEM と FEM の結合モデル

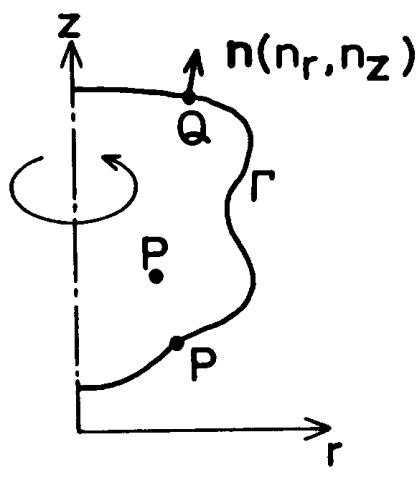

図 2 軸対称の基本解
ここで, $K_{B}=M G^{-1} H$ である.一方，領域 $\Omega^{F}$ に対し ては，次式のような有限要素平衡方程式が得られる。

$$
\boldsymbol{K}_{\boldsymbol{F}} \boldsymbol{U}_{\boldsymbol{F}}=\boldsymbol{F}_{\boldsymbol{F}}
$$

ここで, $\boldsymbol{K}_{\boldsymbol{F}}$ は删性マトリックス， $\boldsymbol{U}_{F}, \boldsymbol{F}_{F}$ はそれぞれ 領域 $\Omega^{F}$ の有限要素の節点変位および節点荷重べクト ルである.さらに，内部境界 $\Gamma^{l}$ 上での適合条件および 平衡条件を用いることにより式(4)，(5)は次の一つ の式にまとめられる(3).

$$
\boldsymbol{K} \boldsymbol{U}=\boldsymbol{F}
$$

ここで， $\boldsymbol{K}, \boldsymbol{U}, \boldsymbol{F}$ は，それぞれ系全体の制性マトリ ックス，節点変位および節点荷重べクトルである。

また，仮想き裂進展法によれば，き裂の進展に伴っ て外力が変化しないような系に対して，エネルギー解 放率 $G$ は次式で与えられる。

$$
G=-\sum_{i=1}^{N_{F}} \frac{1}{2} \boldsymbol{u}_{i}^{\tau} \frac{\Delta \boldsymbol{k}_{i}}{\Delta a} \boldsymbol{u}_{i}
$$

ここで, $\Delta a$ は微小き裂進展量, $\boldsymbol{u}_{i}$ は要素節点変位

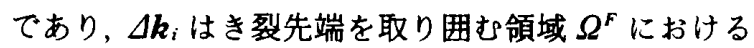
有限要素 $\left(i=1 \sim N_{F}\right)$ の $\Delta a$ に伴う要菜剛性マトリッ クスの変化量である．また，このとき $K_{1}$ 値は，次式の ように与えられる。

$$
K_{\mathrm{I}}=\sqrt{E G /\left(1-\nu^{2}\right)}
$$

ただし，Eは縦弾性係数，レはポアソン比である。

\section{3. 解 析 結 果}

$3 \cdot 1$ 周形き裂を有する丸棒の引强り 図 3 に示 すように，外壁に深さ $a$ の環状き裂が対称軸 ( $z$ 軸)に 垂直に入っている直径 $2 d$, 長さ $2 H$ の丸棒が, 両端で 一様引張応力 $\sigma_{0}$ を受けている問題を考えた。なお, 解 析は，図 4 に要素分割の例を示すように, $r$ 軸面での

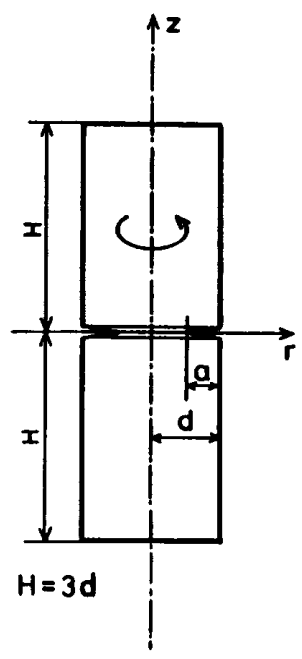

図 3 周形き裂を 有する丸棒

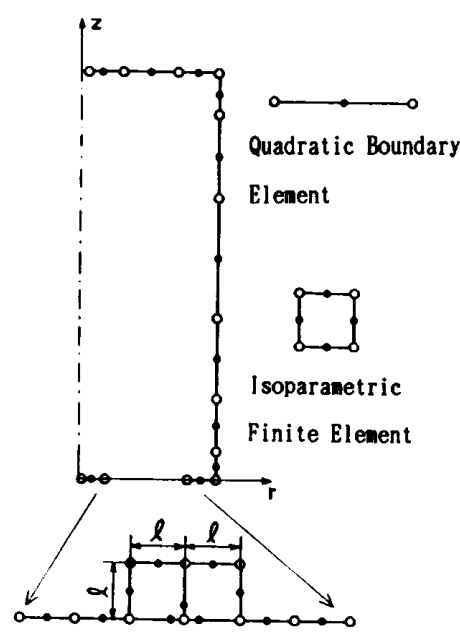

図 4 要素分割図 $(a / d=0.5, \quad l / a=0.2)$ 
対称性を考虑した $1 / 2$ 部分について行い，き裂先端部 に二つの 8 節点アイソパラメトリック有限要素を配置 し，その他の部分には 2 次の境界要素を用いた。ただ し, $z$ 軸に接する境界要素については, $z$ 軸上に節点 をとると，式（3)におけるマトリックス $\boldsymbol{G}$ が正則で なくなり，逆行列 $\boldsymbol{G}^{-1}$ を求めることができなくなる ため, $z$ 軸に接する境界要素についてのみ, 図 5 に示 すような, 非適合要素を用いた。また，解析結果は， $F_{1}$ $\left(=K_{1} / \sigma_{0} \sqrt{\pi a}\right)$ という無次元化した形で示し, 本解析結 果の精度を評価するために西谷・野田による体䅡力法 による解析值 ${ }^{(7)}$ を参照解 $\left(F_{1}^{*}\right)$ として用いた，なお，以 下の解析は, すべて, ポアソン比 0.3 とし, 倍精度で 計算を行った。

まず，き裂先端の有限要素の大きさの適正範囲を調 べるために, き裂長さ $a / d=0.5$ の場合について, 有限 要素の大きさlを変化させて解析を行った。この場合 の解析結果について, l/a と, 本解析結果と参照解と の相対偏差の関係を図 6 に示す。このとき，仮想き裂 進展量 $\Delta a$ は， $\Delta a / l=10^{-8} \sim 10^{-6}$ にとった，図 6 より， $l / a=0.01 \sim 0.3$ の範囲において, 解析結果はほほ一定 となっていることがわかる。

また，仮想き裂進展量 $\Delta a$ についても，a/d=0.5, $l / a=0.2$ の場合について, $\Delta a$ を変化させて解析を行 い，解析結果に与える影響を調べた。その結果を図 7 に示す。こ机より, $\Delta a / l=10^{-11} \sim 10^{-3}$ の非常に広い範

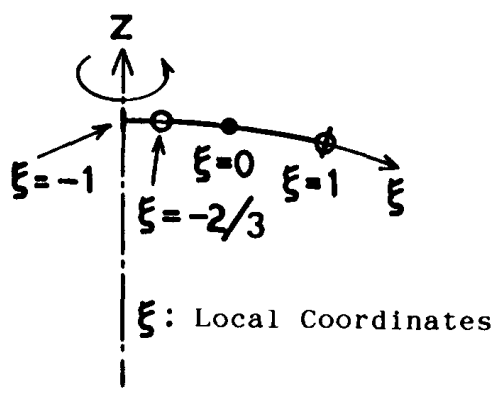

図 5 非適合要素

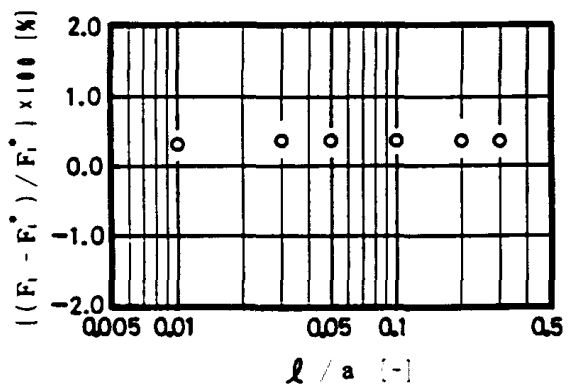

図 6 き裂先端有限要素が解析精度に与える影䇾
囲で解析值は一定となっていることがわかる。ここで， $\Delta a$ が非常に小さいところで，精度が急速に低下する のは，計算機のけた落ちによるものであり， $\Delta a / l$ が $10^{-3}$ 以上においての精度の低下は，差分近似における 微小き裂進展の前提が満たされなくなるためと考えら れる.

次に，ald 0.1 から 0.9 まで変化させて解析を行 つた結果を，参照解とともに表 1 に示す。本解析結果 と参照解とは，良い一致を示していることがわかる。 なお，解析は， $0.067 \leqq l / a \leqq 0.2,5 \times 10^{-8} \leqq \Delta a / l \leqq 1.5 \times$ $10^{-7}$ で行った。

3.2 外壁に周形き裂を有する円管の引張り 第 二の例として, 図 8 に示すような, 外径 $2 B$, 内径 $2(B-d)$, 長さ $2 H て ゙$, 外壁に $z$ 軸に垂直に深さ $a$ の き裂が入っている円管が, 端部に一様引張応力 $\sigma_{0}$ を 受けている場合について, 解析を行った。解析は， $d / B$ $=0.025,0.05,0.075,0.1,0.15,0.20$ の各場合につ いて,$a / d=0.1 \sim 0.9$ まで変化させて行い, 結果は, $F_{1}$ $\left(=K_{1} / \sigma_{0} \sqrt{\pi a}\right)$ という無次元化した形で整理した。ざら に, $F_{1}$ が次式のような $x(=a / d), y(=d / B)$ の関数

表 1 周形き裂を有する丸棒の引張りにおける 応力拡大係数

\begin{tabular}{lcccc}
\hline a d d & $\begin{array}{c}\text { No. of } \\
\text { Nodes }\end{array}$ & F I & F I & $\begin{array}{c}\text { D E V } \\
{[\%]}\end{array}$ \\
\hline 0.1 & 55 & 1.185 & 1.180 & +0.42 \\
0.2 & 51 & 1.267 & 1.261 & +0.48 \\
0.3 & 47 & 1.398 & 1.393 & +0.36 \\
0.4 & 45 & 1.608 & 1.602 & +0.37 \\
0.5 & 43 & 1.947 & 1.940 & +0.36 \\
0.6 & 41 & 2.526 & 2.516 & +0.40 \\
0.7 & 43 & 3.634 & 3.618 & +0.44 \\
0.8 & 45 & 6.271 & 6.243 & +0.45 \\
0.9 & 41 & 16.76 & 16.67 & +0.54 \\
\hline
\end{tabular}

$D E V=((F I-F(t) / F \quad) \times 100 \quad[x]$

$\mathrm{F} I=K I / \sigma \circ \sqrt{\pi \mathrm{a}}, \quad \mathrm{F} I=K \mathrm{I} / \sigma \circ \sqrt{\pi \mathrm{a}}$

F I, K I : Present solution

F f, K : H. Nishitani and N. Noda's solution

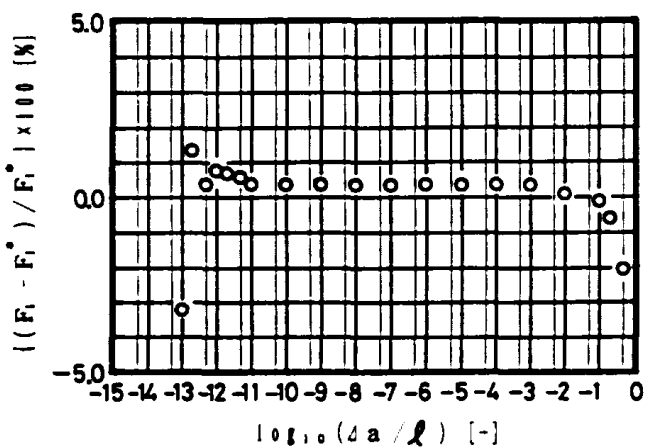

図 7 仮想き裂進展量が解析精度に与える影箩 
で表されると仮定し，最小二乗法によって，表 2 に示 す係数 $C_{i j}(i=0,4 ; j=0,4)$ を決定した。解析結果と, 近似式 $(9)$ •表 2 を用いた計算値との偏差は, $\pm 0.8 \%$ 以下である.また, 解析結果および近似式による， $d / B$ および a $/ d$ と $F_{1}$ の関係を図 9 に示す. 図中では, 解析 值を○印で，近似式を線で示してある。

$$
F_{1}=\sum_{j=0}^{4} \sum_{i=0}^{4} C_{i j} \frac{x^{i}}{1-x} y^{j-1}
$$

\section{3・3 内壁に周形き裂を有する内管の引張り 第} 三の例として, 図 10 に示すような, 外径 $2 B$, 内径

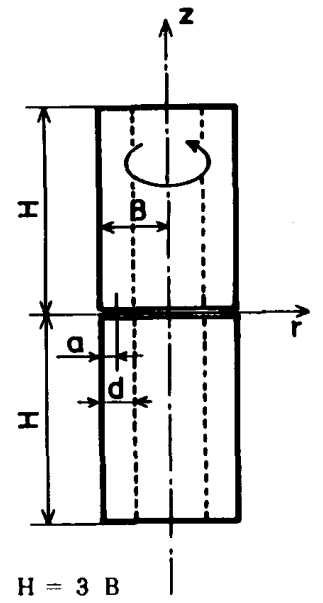

図 8 外壁に周形き裂 を有する円管

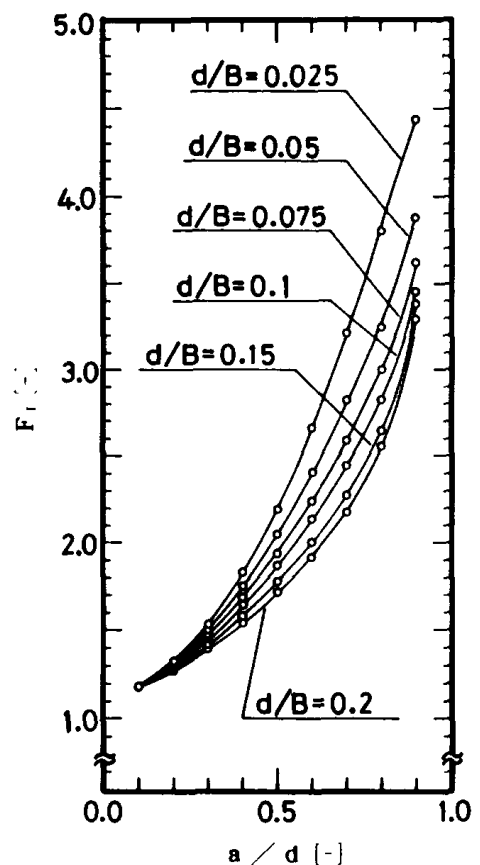

図 9 外壁に周形き裂を有寸る 円管のき裂の応力拡大俰数
$2(B-d)$, 長さ $2 H て ゙$, 内壁に $z$ 軸に垂直に深さ $a$ の き裂が入っている円管が, 端部に一様引張応力 $\sigma_{0}$ を 受けている場合について, 解析を行った。解析は, $d / B$ $=0.025,0.05,0.075,0.1,0.15,0.20$ の各場合について, $a / d=0.1 \sim 0.9$ まで変化させて行い，結果は，外壁き裂 を有する円管の場合と同様に無次元化し, 同じ式 ( 9 ) で近似されるとして，係数 $C_{i j}$ を決定した。結果を，表 3 に示す.解析結果と, 近似式 $(9) \cdot$ 表 3 を用いた計算 值との偏差は， $\pm 0.8 \%$ 以下である。また，解析結果お よび近似式による $d / B \cdot a / d$ と $F_{1}$ の関係を図 9 と同

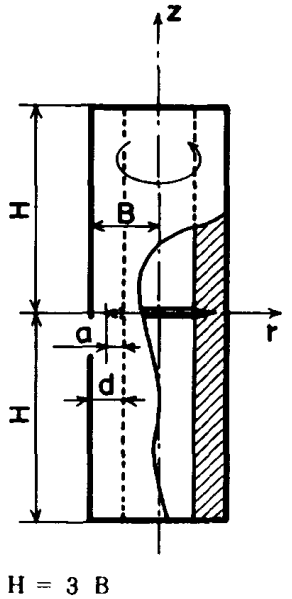

図 10 内壁に周形き裂 を有する円管

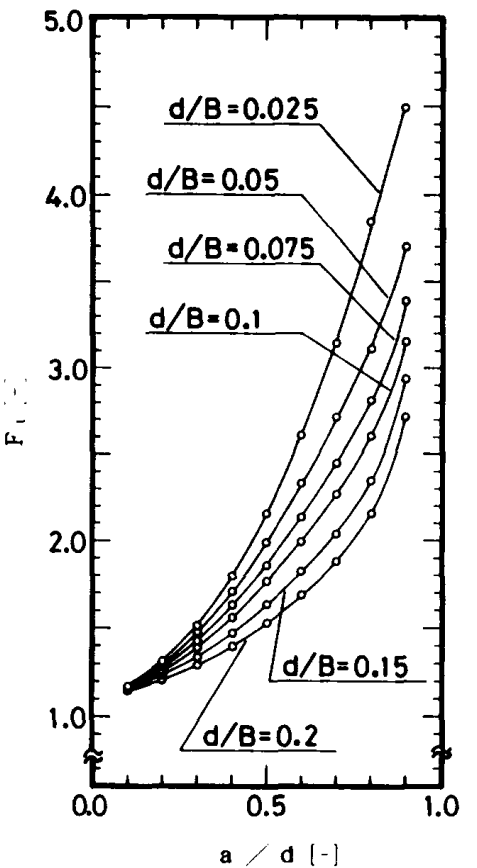

図 11 内壁に周形き裂を有する 円管のき裂の応力拡大係数

表 2 外壁に周形き裂を有する円管の引張りにおける応力拡大係数の近似式の保数

\begin{tabular}{cccccc}
\hline $\mathrm{i}$ & $\mathrm{C}_{10}$ & $\mathrm{C}_{11}$ & \multicolumn{1}{c}{$\mathrm{C}_{12}$} & $\mathrm{C}_{13}$ & \multicolumn{1}{c}{$\mathrm{C}_{14}$} \\
\hline 0 & -0.000100 & 1.1296 & -0.17882 & 0.69963 & -1.9593 \\
1 & 0.011510 & -1.4977 & 10.987 & -61.581 & 142.00 \\
2 & -0.094677 & 8.8599 & -97.314 & 532.42 & -1170.5 \\
3 & 0.21762 & -14.577 & 157.21 & -894.34 & 2027.6 \\
4 & -0.13903 & 6.2844 & -73.139 & 445.64 & -1058.4 \\
\hline
\end{tabular}

$(0.025 \leqq d / B \leqq 0.20,0.1 \leqq a / d \leqq 0.9)$

表 3 内壁に周形き裂を有する円管の引張りにおける応力拡大係数の近似式の係数

\begin{tabular}{cccccc}
\hline 1 & $\mathrm{C}_{10}$ & $\mathrm{C}_{11}$ & $\mathrm{C}_{12}$ & $\mathrm{C}_{13}$ & $\mathrm{C}_{14}$ \\
\hline 0 & -0.001857 & 1.1990 & -1.3288 & $\mathbf{7 . 9 2 3 5}$ & $-\mathbf{1 7 . 3 0 7}$ \\
1 & 0.034298 & -2.3953 & 22.858 & -138.14 & $\mathbf{2 8 9 . 9 2}$ \\
2 & -0.19519 & 12.976 & -157.51 & $\mathbf{8 8 3 . 4 9}$ & $-\mathbf{1 8 4 5 . 7}$ \\
3 & 0.37742 & -21.347 & 256.97 & -1465.8 & 3132.5 \\
4 & -0.21825 & 9.7215 & -122.76 & 730.01 & $-\mathbf{1 6 0 8 . 5}$ \\
\hline
\end{tabular}

$(0.025 \leqq d / B \leqq 0.20,0.1 \leqq a / d \leqq 0.9)$ 
様に, 図 11 に示す。

\section{4. 結}

本報では，き裂先端部に有限要素を配置し，その他 の領域を境界要素を用いて離散化し，有限要素領域に 仮想き裂進展法を組込んで応力拡大係数を求める方法 を軸対称問題に適用した。本手法を用いて，周形き裂 を有する丸棒，外壁に周形き裂を有する円管，内壁に 周形き裂を有する円管がそれぞれ引張りを受ける場合 について解析を行った。これにより，次のような結果 が得られた。

（1）軸対称問題においてき裂が平面状である場 合，き裂先端に大きな有限要素を配置することが可能 である，本報においては， $l / a=0.3$ としても解の精度 の低下は見られなかった。

（2）境界要素法と有限要素法の結合解法に仮想き
裂進展法を組込む方法により，軸対称き裂問題に対し て, 諤差 $1 \%$ 以内の精度で応力拡大係数を求められる ことが期待できる。

（3）通常使用される円管が内，外壁に周形き裂を 有する場合を想定して，このき裂の応力拡大係数の解 析を行い, 最小二乗法によって, 近似式を作成した。

\section{文献}

(1) Parks, D. M., Int. J. Fract., 10 (1974), 485.

(2) Hellen. T. K.. Int. J. Numer. Methods Eng., 9 (1975), 187.

（3）宮崎，浮か 2 名，機論，55-509，A (1989)，101.

（4）宮崎。潘 2 名。機論, 55-513, A (1989), 1180.

(5) Bakr, A. A. and Fenner, R. T., J. Srrain Anlysis, 18-4 (1983). 239.

（6）票，山地，川崎重工技報，79(1982)，1

（7）西谷，野田，機論，50-453，A(1984)，847 